\title{
PRODUÇÃO DE INOCULANTE MICORRÍZICO ON FARM UTILIZANDO RESÍDUOS DA INDÚSTRIA FLORESTAL ${ }^{(1)}$
}

\author{
Marlon João Czerniak ${ }^{(2)} \&$ Sidney Luiz Stürmer ${ }^{(3)}$
}

\begin{abstract}
RESUMO
A produção de inoculante à base de fungos micorrízicos arbusculares (FMAs) utilizando o método on farm é uma alternativa para estimular o uso de inoculante microbiano no sistema de produção vegetal e reduzir os custos associados com a compra desse produto. $O$ objetivo deste estudo foi avaliar o potencial de resíduos do setor florestal, a casca de Pinus (CP) e o lodo de celulose (LC), como componentes do substrato para a produção de inoculante micorrízico on farm. Plantas de sorgo pré-colonizadas com os FMAs, Claroideoglomus etunicatum RJN101A e Dentiscutata heterogama PNB102A, foram estabelecidas em casa de vegetação por três meses em substrato formado por areia:argila expandida:solo (2:2:1). Após, essas foram transplantadas para sacos plásticos de $20 \mathrm{~L}$ contendo substrato formado por CP ou LC, misturados com casca de arroz carbonizada + solo de barranco (1:1:1). O experimento seguiu um fatorial $2 \times 2$, sendo dois isolados fúngicos e dois resíduos, com cinco repetições, em delineamento inteiramente casualizado. As plantas cresceram por três meses sob condições ambientais e, após esse período, $o$ substrato foi analisado quanto ao número de esporos de FMAs, à colonização micorrízica da planta hospedeira e ao potencial de inóculo pelo método do NMP (número mais provável). $\mathrm{O}$ substrato foi dividido em três camadas (superior, mediana e inferior) e apenas o número de esporos foi avaliado individualmente para cada camada. O número de esporos de ambos FMAs não foi influenciado pelo tipo resíduo, mas diminuiu da parte superior para a inferior dentro de cada unidade experimental. $D$. heterogama tendeu a produzir maior número de esporos do que C. etunicatum. A porcentagem de colonização micorrízica do sorgo pelos FMAs foi significativamente maior no resíduo $\mathrm{LC}$ do que $\mathrm{CP}$. O número de propágulos infectivos de FMAs tendeu também a ser maior em LC (22 a 28 propágulos $\mathrm{cm}^{-3}$ substrato) do que em CP (1,6 a 6,5 propágulos $\mathrm{cm}^{-3}$ substrato). O resíduo LC tem
\end{abstract}

(1) Parte da Dissertação de Mestrado do primeiro autor apresentada ao programa de Pós-Graduação em Engenharia Ambiental da Universidade Regional de Blumenau - FURB. Recebido para publicação em 22 de abril de 2014 e aprovado em 20 de agosto de 2014.

(2) Mestre, Programa de Pós-Graduação em Engenharia Ambiental, FURB. Rua São Paulo, 3250. Caixa Postal 1507. CEP 89012900 Blumenau (SC), Brasil. Bolsista da CAPES. E-mail: mjc22sc@hotmail.com

(3) Professor, Departamento de Ciências Naturais, FURB. Rua Antônio da Veiga, 140. Caixa Postal 1507. CEP 89012-900 Blumenau (SC), Brasil. Bolsista de produtividade do CNPq. E-mail: sturmer@furb.br 


\begin{abstract}
potencial para ser utilizado como componente do substrato em sistemas de produção de inoculante micorrízico on farm.
\end{abstract}
Termos de indexação: micorrizas, potencial de inóculo micorrízico, número de esporos, biofertilizantes, Claroideoglomus etunicatum, Dentiscutata heterogama.

\title{
SUMMARY: ON-FARM PRODUCTION OF MYCORRHIZAL INOCULUM USING RESIDUES FROM THE FORESTRY INDUSTRY
}

\begin{abstract}
Production of arbuscular mycorrhizal fungi (AMF) inoculum using the on-farm method is an alternative to stimulate the use of microbial inoculant in plant production systems and to reduce the cost associated with purchase of this product. The goal of this study was to evaluate the potential of residues from the forestry industry, pine bark (CP) and pulp sludge (LC), as components of the substrate used to produce on-farm mycorrhizal inoculum. Sorghum plants pre-colonized with the AMFs Claroideoglomus etunicatum RJN101A and Dentiscutata heterogama PNB102A were established in a greenhouse for three months in a substrate of sand:expanded clay:soil (2:2:1). After this period, plants were transplanted to $20 \mathrm{~L}$ plastic bags containing a substrate with CP or LC mixed with carbonized rice hulls + soil (1:1:1). The experiment followed a $2 \times 2$ factorial arrangement, of two fungal isolates and two residues, with five replicates, in a completely randomized design. Plants were grown outdoors for three months and then the substrate was analyzed for AMF spore numbers, mycorrhizal colonization of the host plant, and inoculum potential by the MPN (most probable number) method. The substrate of each bag was divided into three layers (upper, middle, and lower portion) and only the number of spores was analyzed separately for each layer. The type of residue did not affect the number of spores of either AMF, but this number decreased from the upper to the lower layer within each experimental unit. D. heterogama tended to produce more spores than C. etunicatum. Sorghum mycorrhizal colonization by AMF was significantly greater in the LC residue than in the CP residue. The number of AMF infective propagules also tended to be

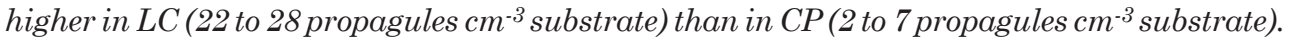
The LC residue showed potential for use as a component of the substrate in mycorrhizal inoculum production systems using the on-farm method.
\end{abstract}

Index terms: mycorrhiza, mycorrhizal inoculum potential, number of spores, biofertilizers, Claroideoglomus etunicatum, Dentiscutata heterogama.

\section{INTRODUÇÃO}

A geração de resíduos nos processos produtivos da indústria florestal é uma consequência inevitável e, de acordo com a Política Nacional de Resíduos Sólidos, as empresas e indústrias têm a responsabilidade de gerenciar esses resíduos gerados nos mais diversos setores de produção (Brasil, 2010). Dessa forma, os programas de gerenciamento de resíduos devem buscar alternativas para reciclagem e aproveitamento desses. As fábricas de papel e produtos derivados de celulose deparam-se com problemas de ordem ambiental, em razão da grande quantidade de resíduos gerados: aproximadamente $48 \mathrm{t}$ de resíduos para cada $100 \mathrm{t}$ de celulose produzida (Bellote et al., 1998). Entretanto, nas indústrias de desdobramento de madeira, a transformação de uma tora em tábuas gera $60 \%$ de resíduos (e.g. cascas, aparas de plaina, aparas do corte e pó de serra) (Ferreira et al., 1989). Por causa da presença de nutrientes na composição desses resíduos, esses podem ser utilizados como fertilizantes e corretivos do solo, por apresentarem características favoráveis aos atributos físicos, químicos e biológicos do solo (Barretto, 2008).
Um destino alternativo para os resíduos do setor florestal pode ser a sua utilização como um carreador em inoculantes microbianos ou biofertilizantes. Entre os diversos grupos de organismos do solo que influenciam o crescimento das plantas, destacam-se os fungos micorrízicos arbusculares (FMAs - Filo Glomeromycota), que estabelecem a associação micorrízica arbuscular (MA) com aproximadamente $80 \%$ das espécies vegetais (Smith \& Read, 2008). Nessa associação, os FMAs formam uma rede de hifas que pode atingir $100 \mathrm{~m} \mathrm{~cm}^{-3}$ solo (Miller et al., 1995), aumentando a área de absorção de nutrientes com baixa mobilidade no solo, principalmente o P (Finlay, 2008). Como resultado, a associação MA influencia na sobrevivência, crescimento e nutrição das plantas, incluindo espécies florestais nativas (Siqueira et al., 1998; Zangaro et al., 2000; Siqueira \& Saggin-Júnior, 2001; Patreze \& Cordeiro, 2005; Pasqualini et al., 2007).

No entanto, a aplicação desses fungos no Brasil em larga escala como biofertilizantes ainda é limitada, principalmente pela falta de um inoculante aceito comercialmente (Siqueira et al., 2002). A 
multiplicação em larga escala de FMAs para a formulação de um inoculante pode ser feita em sistemas à base de um substrato mineral, aeropônicos, hidropônicos ou in vitro (Ijdo et al., 2011). Inoculantes micorrízicos comerciais são disponíveis nos mercados de vários países e os custos associados à sua produção, como estabelecimento de culturas puras, transporte do inoculante, desenvolvimento do carreador, são absorvidos pelos usuários finais que incluem agricultores e viveiristas (Douds Jr. et al., 2006). Uma alternativa para elevar o uso e a aceitação de um biofertilizante à base de FMAs é o desenvolvimento de um inoculante produzido pelo método on farm, que é produzido pelo usuário final no local onde será posteriormente utilizado, evitando os custos associados com a compra de um produto comercial (Douds Jr. et al., 2006; Sharma \& Adholeya, 2011). O inoculante on farm pode ser desenvolvido sob condições ambientais naturais, não necessitando de uma estrutura específica, como estufa, para tal finalidade, multiplicando espécies de FMAs cuja eficiência é conhecida ou mesmo FMAs indígenas de determinada área (Sreenivasa, 1992). A multiplicação dos FMAs na formulação do inoculante on farm tem sido feita em solo fumigado ou em substratos compostados diluídos com vermiculita ou perlita, com diferentes espécies hospedeiras como Brachiaria decumbens, Sorghum sudanense, Zea mays e Paspalum notatum (Douds Jr. et al., 2005).

A produção de inoculante micorrízico pelo método on farm vem sendo empregada em alguns países, utilizando diferentes métodos. Na Colômbia, Sieverding (1991) inoculou Rhizophagus manihotis (R.H. Howeler, Sieverd. \& N.C. Schenck) Walker \& Schüssler (sin. Glomus manihotis) em canteiros com solo desinfestado por fumigação e semeou $B$. decumbens. Após seis meses, 87-99 \% dos esporos recuperados foram de $R$. manihotis, e foi possível produzir $5.000 \mathrm{~L}$ de inóculo em uma área de $25 \mathrm{~m}^{2}$. Na Índia, Gaur et al. (2000) produziram inoculante on farm em canteiros elevados utilizando uma mistura de solo, composto à base de folhas e espécies olerícolas como hospedeiras. Dessa forma, o produtor tem um ganho econômico não apenas com o inoculante produzido, mas também com o uso ou venda das espécies olerícolas. Nos Estados Unidos, Douds Jr. et al. $(2006 ; 2008)$ desenvolveram um método usando canteiros elevados ou sacos plásticos, contendo misturas de solo, vermiculita, e substratos compostados e inoculados com plantas pré-colonizadas de Paspalum notatum. No Brasil, Schlemper \& Stürmer (2014) adaptaram a técnica de Douds Jr. et al. (2008) e utilizaram resíduos lignocelulósicos não compostados, como bagaço de cana-de-açúcar, bainhas de palmeira real, misturados com casca de arroz e solo, e plantas pré-colonizadas de Sorghum bicolor para produzir inoculante micorrízico on farm. Neste estudo, o número mais provável de propágulos variou de 233 a $350 \mathrm{~cm}^{-3}$, caracterizando-o como um inoculante com alto potencial infectivo.
O Estado de Santa Catarina destaca-se com a segunda maior área de plantio de Pinus do Brasil (538.254 ha), que corresponde a $32,8 \%$ do total da área plantada (ABRAF, 2012). Essa elevada atividade industrial com o uso de Pinus para a produção de papel e celulose e painéis de madeira gera grande quantidade de resíduos, principalmente lodo de celulose e casca de Pinus. Considerando os benefícios de um biofertilizante à base de FMAs para promover o crescimento vegetal e a diminuição no uso dos fertilizantes fosfatados, a falta de um inoculante à base de FMAs aceito comercialmente no Brasil e a possibilidade de viabilizar um destino alternativo aos resíduos da indústria florestal, o objetivo deste trabalho foi avaliar um inoculante micorrízico produzido pelo sistema on farm, utilizando os resíduos casca de Pinus e lodo de celulose como componentes do substrato.

\section{MATERIAL E MÉTODOS}

\section{Local do estudo}

O experimento para a produção de inoculante micorrízico on farm foi implantado no Horto Florestal do Campus V da Universidade Regional de Blumenau (FURB). O clima é caracterizado como subtropical úmido (Cfb de Köppen), com temperatura média anual de $20^{\circ} \mathrm{C}$ e pluviosidade média de $2.000 \mathrm{~mm}^{-1} \mathrm{ano}^{-1}$. A produção do inoculante micorrízico foi realizada a céu aberto entre 16 de janeiro a 16 de abril de 2013 . Nesse período, a precipitação pluvial média foi de $3,33 \mathrm{~mm} \mathrm{dia}^{-1}$, com temperatura mínima registrada de $12{ }^{\circ} \mathrm{C}$ e a máxima de $32{ }^{\circ} \mathrm{C}$.

\section{Resíduos da indústria florestal}

Os resíduos testados foram obtidos de uma empresa privada do setor de papel e celulose. Os resíduos, cuja caracterização físico-química é apresentada no quadro 1, foram os seguintes:

Casca de Pinus (CP): esse resíduo é gerado no processamento das toras de Pinus e não possui propriedades fertilizantes em razão da sua baixa concentração de nutrientes (Blum, 1998). Contudo, a $\mathrm{CP}$ pode ser incorporada ao solo para melhorar suas propriedades físicas após sua secagem e moagem (Odneal \& Kaps, 1990). Esse resíduo é normalmente descartado ou queimado. O resíduo $\mathrm{CP}$ foi coletado do pátio de tratamento de armazenamento de resíduos da empresa, estava exposto a céu aberto durante um período de aproximadamente um ano e não sofreu nenhum tipo de tratamento; $\mathrm{e}$

Lodo de celulose (LC): esse resíduo possui teores elevados de alguns nutrientes e pode ser utilizado como fertilizante e condicionador de solo. LC apresenta elevado teor de matéria orgânica e baixos teores de $\mathrm{Al}$ e Na; seus teores de K são muito baixos e seu uso como fertilizante necessita de complementação com fertilizante potássico (Fabres et al., 1994). O resíduo 
Quadro 1. Caracterização físico-química do lodo de celulose, da casca de Pinus e da casca de arroz utilizados como componentes do substratos na produção de inoculante micorrízico on farm

\begin{tabular}{|c|c|c|c|c|c|c|}
\hline Resíduo & $\mathrm{pH}\left(\mathrm{CaCl}_{2}\right)$ & $\mathbf{P}^{(1)}$ & $\mathbf{K}$ & $\mathrm{N}$ & $\mathbf{C a}$ & $\mathrm{Mg}$ \\
\hline & & & & $\mathrm{g} \mathrm{kg}^{-1}$ & & \\
\hline Casca de Pinus (CP) & 5,8 & 0,07 & 0,14 & 8,9 & 4,9 & 0,7 \\
\hline Lodo de celulose (LC) & 6,9 & 0,09 & 0,13 & 10,1 & 1,7 & 0,3 \\
\hline Casca de arroz carbonizada & 7,4 & 0,11 & 0,19 & 1,9 & 3,5 & 0,8 \\
\hline
\end{tabular}

(1) Valores representam o teor total de cada elemento.

LC foi proveniente das lagoas de tratamento de efluentes da empresa. Depois de retirado dessas lagoas, o lodo ficou exposto ao ambiente natural por aproximadamente um ano para reduzir a umidade e posteriormente armazenado em galpões cobertos.

\section{Isolados de FMAs}

Os isolados de FMAs utilizados foram Claroideoglomus etunicatum (W.N. Becker \& Gerd.) Walker \& Schüssler RJN101A (Família Claroideoglomeraceae) e Dentiscutata heterogama (T.H. Nicolson \& Gerd.) Sieverd., F.A. Souza \& Oehl PNB102A (Família Gigasporaceae), obtidos da Coleção Internacional de Cultura de Glomeromycota (CICG www.furb.br/cicg - Universidade Regional de Blumenau, Blumenau, SC). Os fungos foram selecionados para este estudo por pertencerem a famílias diferentes e pelo fato de que membros de Gigasporaceae raramente são componentes de inoculante micorrízico on farm. Inóculo de culturas puras desses fungos, contendo esporos, hifas e pedaços de raízes colonizadas, foi diluído (10 \%) em substrato padrão da CICG, composto de uma mistura de areia:argila expandida:solo $(2: 2: 1, \mathrm{pH}=$ $6,0)$. Após, essa mistura foi acondicionada em tubetes plásticos de $270 \mathrm{~mL}$ e semeados com sorgo (Sorghum bicolor (L.) Moench). Três plantas foram deixadas por tubetes após a emergência das plântulas e essas foram mantidas em casa de vegetação por três meses. Essas plantas précolonizadas de sorgo foram utilizadas na produção do inoculante micorrízico on farm.

\section{Produção do inoculante micorrízico on farm}

Os resíduos do CP e LC foram misturados separadamente com amostras de solo de barranco e casca de arroz carbonizada na proporção de 1:1:1. Essa mistura é denominada como substrato para fins deste artigo. A casca de arroz carbonizada foi proveniente de uma empresa comercial e suas propriedades físicoquímicas são apresentadas no quadro 1 . O solo foi proveniente de uma área localizada no Campus $\mathrm{V}$ da Universidade Regional de Blumenau e possuía textura franco-siltosa. As propriedades químicas dele são: $\mathrm{pH}=4,1$ (em água, $1: 1$ ), $\mathrm{P}=25,6 \mathrm{mg} \mathrm{dm}^{-3}, \mathrm{~K}=206,1$ $\mathrm{mg} \mathrm{dm}{ }^{-3}, \mathrm{Al}=2.0 \mathrm{cmol}_{\mathrm{c}} \mathrm{dm}^{-3}, \mathrm{Ca}=1,2 \mathrm{cmol}_{\mathrm{c}} \mathrm{dm}^{-3}$, $\mathrm{Mg}=0,4 \mathrm{cmol}_{\mathrm{c}} \mathrm{dm}^{-3}$ e matéria orgânica $=0,7 \%$.
O substrato foi acondicionado em sacos plásticos reciclados de polietileno de baixa densidade de $50 \mathrm{~cm}$ de altura com capacidade de $20 \mathrm{~L}$, com 34 orifícios para permitir o fluxo de água. Os sacos foram preenchidos com $18 \mathrm{~L}$ de cada substrato e considerados como uma unidade experimental (= repetição) dentro de cada tratamento. Três covas foram feitas na superfície do substrato de cada saco com o auxílio de um tubete plástico de $270 \mathrm{~mL}$ (Figura 1a). Nessas covas, foram transplantadas as mudas de sorgo précolonizadas com os isolados de FMAs, totalizando nove plantas por saco (Figura 1b); após, os sacos foram dispostos sobre manta geotêxtil para evitar contato direto com o solo (Figura 1c). O experimento seguiu um delineamento inteiramente casualizado, em esquema fatorial $2 \times 2$, sendo dois resíduos ( $\mathrm{LC} \mathrm{e}$ $\mathrm{CP}$ ) e dois isolados de FMAs (C. etunicatum e $D$. heterogama) com cinco repetições.

$\mathrm{Na}$ colheita do experimento, a parte aérea das plantas foi descartada, e o conteúdo de cada saco estratificado em seção superior $(0-15 \mathrm{~cm})$, mediana $(15-30 \mathrm{~cm})$ e inferior $(30-45 \mathrm{~cm})$. Amostras de $1 \mathrm{~L}$ do conteúdo de cada seção foram retiradas de cada unidade experimental e armazenadas em sacos plásticos a $4{ }^{\circ} \mathrm{C}$ até a sua análise.

\section{Análise do inoculante}

As amostras de $1 \mathrm{~L}$ foram homogenizadas e uma alíquota de $100 \mathrm{~mL}$ retirada de cada seção para a extração dos esporos de FMAs via peneiragem úmida (Gerdemann \& Nicolson, 1963), seguida de centrifugação em gradiente de sacarose (20 e $60 \%$ ). Após centrifugação, o material foi colocado em placas de Petri, e os esporos foram contados sob lupa. Os esporos de espécies indígenas encontrados, diferentes das dos isolados utilizados, foram contados separadamente.

A colonização micorrízica foi quantificada em amostras de $0,4 \mathrm{~g}$ de raízes obtidas apenas da seção mediana do substrato. As raízes foram coletadas manualmente com o auxílio de uma pinça, lavadas em água corrente e descoloridas seguindo o método de Koske \& Gemma (1989). Após, essas foram espalhadas sobre uma placa de Petri quadriculada $(1,1 \times 1,1 \mathrm{~cm})$, e a porcentagem de colonização foi mensurada, seguindo o método da intersecção das linhas em placa 
quadriculada (malha de $1,1 \times 1,1 \mathrm{~cm}$ ) de Giovannetti $\&$ Mosse (1980).

Amostras de $100 \mathrm{~mL}$ de substrato foram retiradas da seção mediana de cada uma das cinco repetições e combinadas para compor uma amostra composta para cada tratamento. Essa amostra composta foi utilizada
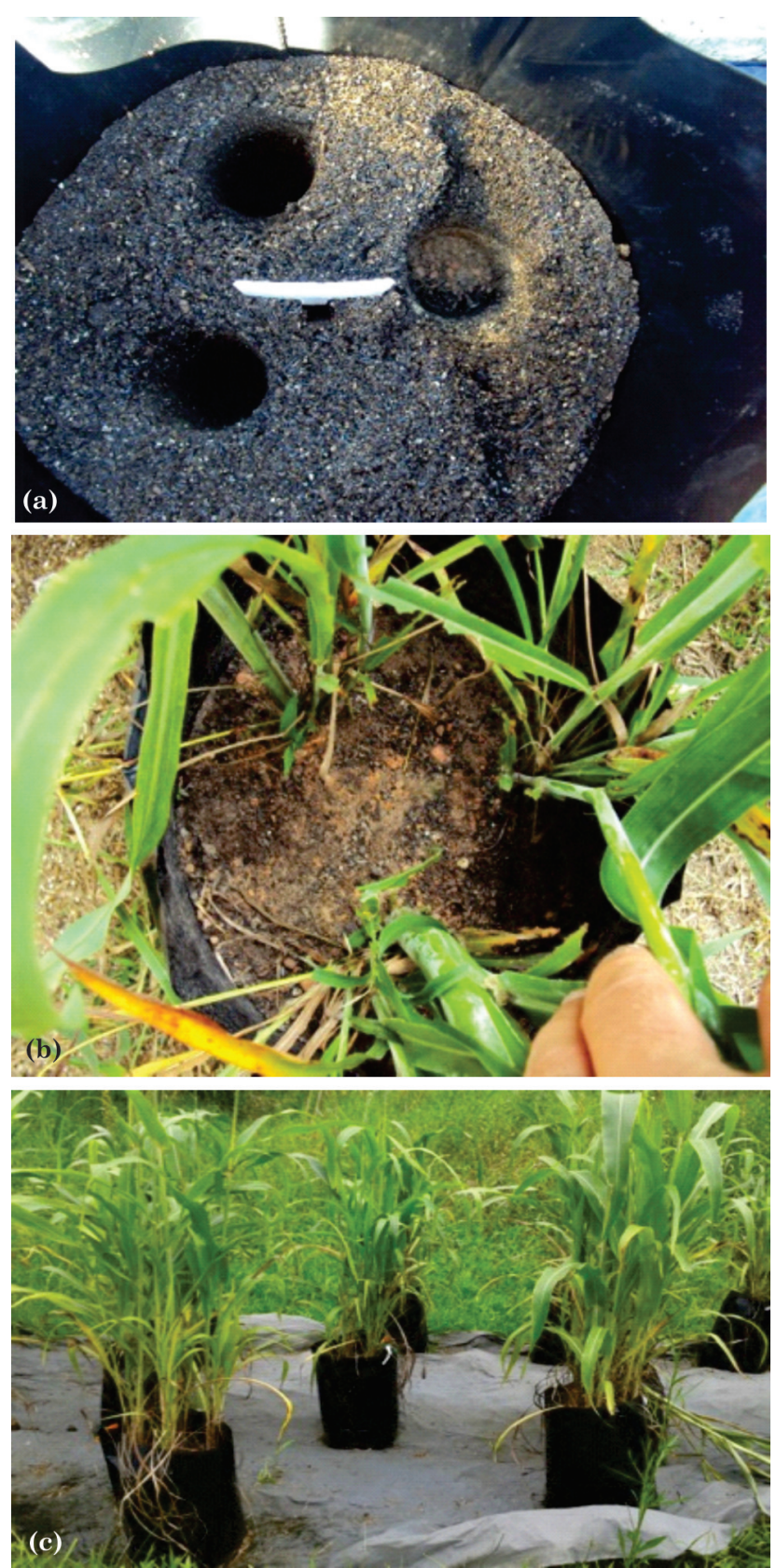

Figura 1. Aspectos do experimento de produção de inoculante micorrízico on farm: (a) Saco com substrato e orifícios pronto para receber mudas de sorgo pré-colonizadas com fungos micorrízicos arbusculares; (b) Plantas de sorgo após 30 dias do transplante; e (c) Disposição dos sacos sobre manta geotêxtil para evitar o contato com o solo. para mensurar o potencial de inóculo micorrízico pelo método do número mais provável (NMP), descrito por Alexander (1965) e apresentado por Bagyaraj \& Stürmer (2010). Para cada tratamento, foram estabelecidas cinco diluições $\left(10^{-1}\right.$ a $\left.10^{-5}\right)$ com cinco repetições. Como diluente, foi utilizada uma mistura de areia e argila expandida (1:1, v/v) esterilizada em autoclave $\left(121^{\circ} \mathrm{C}\right.$ por $\left.90 \mathrm{~min}\right)$. O NMP foi conduzido em cones plásticos de 100 mL e semeado com Sorghum bicolor. Após a emergência, foi deixada apenas uma planta por tubete. Na avaliação após 30 dias em casa de vegetação, a parte aérea foi descartada e as raízes foram retiradas do substrato, lavadas em água corrente e descoloridas de acordo com o método de Koske \& Gemma (1989). As raízes foram dispostas em placas de Petri, avaliadas sob lupa quanto à presença ou ausência de colonização micorrízica em cada diluição. Em razão da restrição de trabalho e espaço em casa de vegetação, apenas um ensaio de NMP foi montado para cada combinação de resíduo e fungo.

\section{Análises estatísticas}

Previamente às análises, o número de esporos foi transformado usando a fórmula log $(x+1)$, e a porcentagem de colonização micorrízica transformada usando arcoseno da raiz quadrada da porcentagem de colonização. O efeito dos tratamentos (resíduos LC e $\mathrm{CP})$ no número de esporos e porcentagem de colonização e o das seções do substrato no número de esporos foram testados por análise de variância simples. Para a comparação das médias, foi aplicado o teste $t$ de Student $(p<0,05)$. Os testes estatísticos foram realizados utilizando o software Statistica ${ }^{\circledR}$ v.7.0.

\section{RESULTADOS}

O número de esporos de C. etunicatum RJN101A não diferiu significativamente entre os resíduos utilizados na composição do substrato, independentemente da seção analisada (Quadro 2). O número médio de esporos diminuiu com a profundidade da seção e a seção superior apresentou os maiores números de esporos (35 a 83,4 em $100 \mathrm{~mL}$ ), enquanto a seção inferior apresentou os menores valores (5 a 6,2 em $100 \mathrm{~mL}$ ) (Quadro 2).

A composição do substrato influenciou significativamente a esporulação de $D$. heterogama PNB102A apenas na seção mediana, cujo número de esporos foi significativamente superior em LC (225,2 esporos em $100 \mathrm{~mL})$, comparado à $\mathrm{CP}$ (71,6 esporos em $100 \mathrm{~mL})$. O número médio de esporos para $D$. heterogama também tendeu a diminuir com a profundidade da seção com os maiores valores obtidos nas seções superiores e medianas de cada resíduo (Quadro 2).

O número de esporos de FMAs indígenas nos substratos inoculados com $D$. heterogama não diferiu 
Quadro 2. Número de esporos de isolados de Claroideoglomus etunicatum RJN101A e Dentiscutata heterogama PNB102A produzidos em sistema on farm em substrato contendo lodo de celulose e casca de Pinus, nas diferentes seções. Valores representam médias \pm desviopadrão $(\mathbf{n}=5)$

\begin{tabular}{lcc}
\hline FMA inoculado/ & \multicolumn{2}{c}{ Componente do substrato } \\
\cline { 2 - 3 } Seção & Lodo de celulose & Casca de Pinus \\
\hline & $\mathrm{N}^{\circ}$ de esporo $100 \mathrm{~mL}^{-1}$ \\
C. etunicatum RJN101A & & \\
Superior & $35,0 \pm 24,5 \mathrm{aA}$ & $83,4 \pm 47,2 \mathrm{aA}$ \\
Mediana & $13,4 \pm 10,6 \mathrm{aAB}$ & $16,4 \pm 13,4 \mathrm{aBC}$ \\
Inferior & $6,2 \pm 4,5 \mathrm{aB}$ & $5,0 \pm 2,9 \mathrm{aC}$ \\
D. heterogama PNB102A & & \\
Superior & $327,0 \pm 70,1 \mathrm{aA}$ & $284,2 \pm 105,6 \mathrm{aA}$ \\
Mediana & $225,2 \pm 49,7 \mathrm{aB}$ & $71,6 \pm 37,5 \mathrm{bBC}$ \\
Inferior & $24,6 \pm 15,5 \mathrm{aC}$ & $30,6 \pm 21,0 \mathrm{aC}$ \\
\hline
\end{tabular}

Letras minúsculas nas linhas comparam as médias entre os substratos na mesma seção (superior, mediana e inferior), e letras maiúsculas nas colunas comparam médias nas diferentes seções no mesmo substrato para cada fungo. Médias seguidas por letras iguais não diferem significativamente $(\mathrm{p}<0,05)$ pelo teste $t$ de Student.

significativamente entre as seções e entre os resíduos (Quadro 3). Nos substratos inoculados com $C$. etunicatum, o número de esporos de FMAs indígenas foi significativamente maior nas seções centrais e inferiores em LC do que em CP. Em CP, a esporulação por FMAs indígenas foi significativamente maior na seção superior, comparado com as duas seções inferiores (Quadro 3).

Os substratos utilizados influenciaram significativamente a porcentagem de colonização micorrízica nas raízes de $S$. bicolor, para ambas espécies de FMAs (Figura 2). Os valores de porcentagem de colonização micorrízica foram significativamente maiores em LC do que em CP.

O número mais provável de propágulos infectivos de FMAs presentes no inoculante on farm tendeu a ter os maiores valores no resíduo contendo LC, cujos valores variaram de 22,6 a 28,3 propágulos $\mathrm{cm}^{-3} \mathrm{de}$ substrato (Figura 3).

\section{DISCUSSÃO}

Os resultados deste estudo demonstraram que a utilização de resíduos do setor florestal é viável para compor o substrato a ser utilizado na produção de inoculante micorrízico usando o método on farm. $\mathrm{O}$ inoculante contendo lodo de celulose no substrato destacou-se em relação à casca de Pinus, pois tendeu a apresentar os maiores valores de número de esporos de $D$. heterogama e de colonização micorrízica e

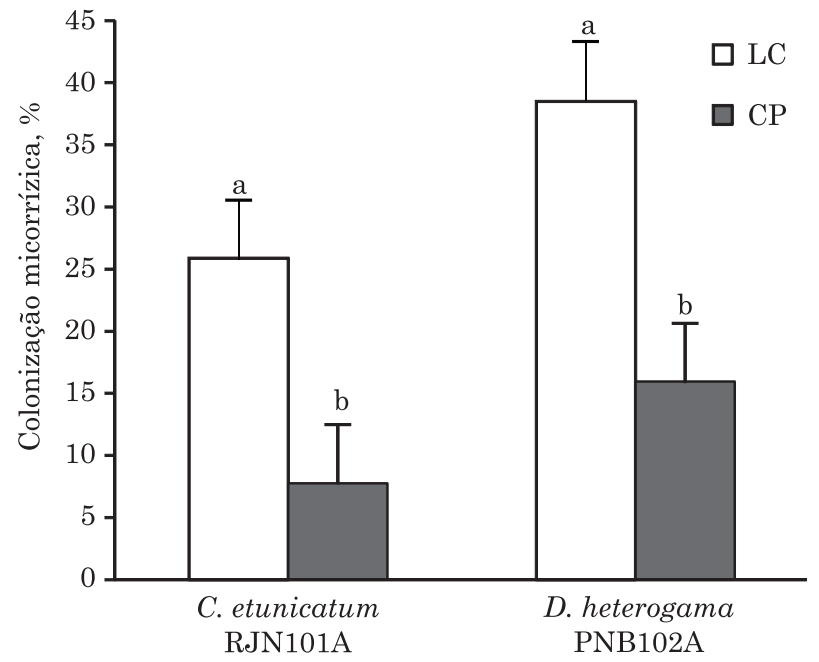

Figura 2. Colonização micorrízica em Sorghum bicolor associado com Claroideoglomus etunicatum RJN101A e Dentiscutata heterogama PNB102A em sistema on farm com substrato à base de lodo de celulose (LC) e casca de Pinus (CP). Letras comparam médias entre os substratos para a mesma espécie de FMA. Médias seguidas por diferentes letras diferem significativamente entre si $(p<0,05)$ pelo teste $t$ de Student.

número de propágulos infectivos para ambos FMAs. Este trabalho representa o primeiro estudo de substratos originados da indústria florestal como alternativa para compor um inoculante micorrízico produzido on farm, uma vez que outros estudos testaram substratos compostados (Douds Jr. et al., 2008) ou resíduos lignocelulósicos (Schlemper \& Stürmer, 2014). Atualmente, há necessidade de melhorar as formulações de inoculantes para desenvolver e comercializar novos produtos biofertilizantes que serão mais eficazes, mais estáveis em longo prazo, de melhor qualidade, para atender as necessidades dos agricultores (Stephens \& Rask, 2000). As dificuldades técnicas relacionadas com a produção em grande escala de um inoculante devem ser superadas; para os FMAs, por serem simbiontes obrigatórios, a produção em larga escala depende de habilidades específicas para o estabelecimento e cultivo deles em culturas puras e de infraestrutura (Dalpé \& Monreal, 2004). Nesse sentido, a produção pelo método on farm surge como alternativa, podendo o inoculante ser produzido pelo próprio agricultor em sua propriedade, diminuindo os problemas com espaço, reduzindo custos pela utilização de componentes baratos para compor o substrato e evitando o transporte do inoculante até a sua propriedade. Entretanto, o agricultor dependerá de um pré-inóculo inicial a ser adquirido comercialmente, ou poderá usar como pré-inóculo FMAs nativos de sua propriedade (Douds Jr. et al., 2010).

Neste estudo, foi observado que a esporulação por ambos os isolados de FMAs não ocorreu de forma 
homogênea dentro de cada unidade experimental (sacos de $20 \mathrm{~L}$ ) utilizada para produzir o inoculante micorrízico. O número de esporos produzidos foi significativamente maior na seção superior do substrato e tendeu a diminuir nas seções mediana e inferior. Esse padrão de esporulação pode ser o resultado do transplante das mudas de sorgo précolonizadas ter ocorrido na seção superior das unidades

Quadro 3. Número de esporos de FMA indígenas produzidos no sistema on farm em substrato contendo lodo de celulose e casa de Pinus, quando inoculado com plantas pré-colonizadas por Claroideoglomus etunicatum RJN101A e Dentiscutata heterogama PNB102A. Valores representam médias \pm desvio-padrão de cinco repetições

\begin{tabular}{lcc}
\hline FMA inoculado/ & \multicolumn{2}{c}{ Componente do substrato } \\
\cline { 2 - 3 } Seção & Lodo de celulose & Casca de Pinus \\
\hline & $\mathrm{N}^{\mathrm{o}}$ de esporo & $100 \mathrm{~mL}^{-1}$ \\
C. etunicatum RJN101A & & \\
Superior & $43,8 \pm 22,7 \mathrm{aA}$ & $54,4 \pm 34,2 \mathrm{aA}$ \\
Mediana & $57,4 \pm 25,9 \mathrm{aA}$ & $12,6 \pm 3,6 \mathrm{bB}$ \\
Inferior & $30,0 \pm 9,6 \mathrm{aA}$ & $15,2 \pm 5,9 \mathrm{bB}$ \\
D. heterogama PNB102A & & \\
Superior & $37,4 \pm 25,2 \mathrm{aA}$ & $46,2 \pm 34,1 \mathrm{aA}$ \\
Mediana & $53,6 \pm 52,9 \mathrm{aA}$ & $31,6 \pm 29,0 \mathrm{aA}$ \\
Inferior & $40,4 \pm 21,5 \mathrm{aA}$ & $41,2 \pm 44,9 \mathrm{aA}$ \\
\hline
\end{tabular}

Letras minúsculas nas linhas comparam as médias entre os substratos na mesma seção (superior, mediana e inferior), e letras maiúsculas nas colunas comparam diferentes seções no mesmo substrato para cada fungo. Médias seguidas por letras iguais não diferem significativamente $(\mathrm{p}<0,05)$ pelo teste $t$ de Student.

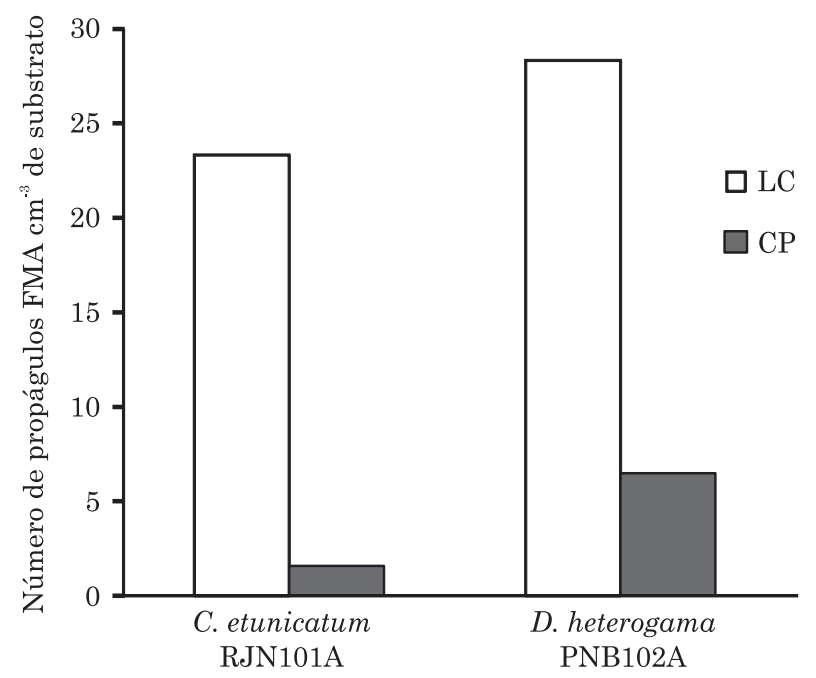

Figura 3. Número de propágulos infectivos de FMA em sistema on farm com substrato à base de lodo de celulose (LC) e casca de Pinus (CP), inoculados com Claroideoglomus etunicatum RJN101A e Dentiscutata heterogama PNB102A. experimentais. Como o tempo de condução do experimento foi de três meses, pode-se hipotetizar que a planta hospedeira não produziu raízes suficientes nas seções medianas e inferiores, o que pode ter influenciado na esporulação dos fungos, que necessitam de uma biomassa mínima dentro do córtex radicular para que o processo de esporulação ocorra (Gazey et al., 1992). Do ponto de vista prático, esse resultado evidenciou que faz-se necessária uma mistura entre as seções para a homogeneização do inóculo produzido ou que sejam utilizadas apenas as seções superiores e medianas. Outros estudos com produção de inoculante micorrízico on farm analisaram a esporulação após a homogeneização do substrato (Gaur et al., 2000; Douds Jr. et al., 2006, 2008; Schlemper \& Stürmer, 2014). De acordo com os resultados obtidos neste estudo, a homogeneização do substrato no sistema on farm pode diluir os esporos produzidos nas seções medianas e superiores, interferindo o potencial de inóculo micorrízico do inoculante como um todo.

Considerando o número de esporos como parâmetro para avaliar o inoculante micorrízico, observou-se que: a esporulação de D. heterogama PNB102A tendeu a ser maior do que a de C. etunicatum RJN101A em ambos os substratos e o número de esporos foi baixo, independentemente do substrato e fungo inoculado. Schlemper \& Stürmer (2014), trabalhando com os mesmos isolados fúngicos em sistema de produção on farm com resíduos de cana-de-açúcar e de palmeira real, encontraram médias de 370 e $<1$ esporos em $100 \mathrm{~mL}$ para C. etunicatum e D. heterogama, respectivamente. Neste estudo, as médias do número de esporos foram de 18-34 para C. etunicatum e de 125-192 para D. heterogama, em $100 \mathrm{~mL}$ de substrato. Essa comparação demonstrou que há grande variação na esporulação de FMAs em razão do tipo de substrato utilizado na multiplicação (Gaur et al., 2000). Em sistema de produção on farm, Douds Jr. et al. (2006), trabalhando com outro isolado de $C$. etunicatum, registraram valores de 24 a 478 esporos em $100 \mathrm{~mL}$ em substrato com esterco bovino + composto de folhas e de 744 a 832 esporos em $100 \mathrm{~mL}$ em substrato à base de composto de poda de jardinagem. Por isso, o número total de esporos produzidos por ambos os fungos no inoculante on farm pode ser considerado baixo. Para um inoculante de $C$. etunicatum, esse baixo número de esporos não necessariamente impacta a qualidade do inoculante, pois outras formas de propágulos, além dos esporos, são capazes de iniciar a colonização micorrízica. No entanto, a avaliação da esporulação é mais critica para $D$. heterogama, uma vez que, para essa espécie e outras pertencentes à família Gigasporaceae, os esporos representam o único propágulo capaz de germinar, penetrar na raiz e estabelecer nova colonização micorrízica (Morton, 1993).

Os resultados da porcentagem de colonização micorrízica nas plantas de sorgo com os dois isolados de FMAs evidenciaram o potencial do LC para uso em 
substrato para a produção de inoculante micorrízico. Para o substrato contendo esse resíduo, a porcentagem de colonização foi $>20 \%$ enquanto no substrato com $\mathrm{CP}$ a colonização variou de 8 a $16 \%$. A mensuração da colonização micorrízica estima o crescimento de um isolado fúngico ou de uma comunidade de FMAs dentro do córtex radicular da planta hospedeira, que pode ou não estar correlacionado com a eficiência dos FMAs em promover o crescimento vegetal. Douds Jr. et al. (2006) observaram que a colonização micorrízica nas plantas hospedeiras usadas para a produção de inoculante micorrízico on farm variou amplamente para um mesmo isolado fúngico em razão do tempo de desenvolvimento das plantas e da adição de formas orgânica e inorgânica de fosfato; por exemplo, a colonização micorrízica de Paspalum notatum por $C$. etunicatum variou de 1,7 a $80,5 \%$; e a de Funneliformis mosseae, de 17,4 a 74,5\%. Schlemper \& Stürmer (2014) observaram que a técnica de inoculação no sistema on farm (transplante de plantas pré-colonizadas ou inoculação direta) também influenciou a colonização micorrízica. Embora a colonização micorrízica das plantas de sorgo cultivadas no substrato com LC tenha sido considerada adequada, a aplicação de isoflavonoides pode estimular a colonização micorrízica (Siqueira et al., 1991), embora os seus efeitos na colonização e esporulação difiram de acordo com o isolado fúngico utilizado (Novais \& Siqueira, 2009). A adição de flavonoides pode acelerar a colonização radicular pelos FMAs (Siqueira et al., 1991) e assim promover o potencial de inóculo micorrrízico; no entanto, essa estratégia na produção de um inoculante micorrízico on farm ainda precisa ser testada.

Os valores de NMP para o potencial de inóculo foram influenciados pelo tipo de resíduo utilizado no substrato e tenderam a ser maiores com o uso do lodo de celulose. No entanto, os valores de NMP no inoculante produzido com LC variaram de 23 a 28 propágulos $\mathrm{cm}^{-3}$ de substrato; dessa forma, não caracterizam uma produção massal de inoculante micorrízico, uma vez que essa preconiza valores superiores a 80-100 propágulos $\mathrm{cm}^{-3}$ solo (Feldmann \& Grotkass, 2002). A técnica de avaliação pelo NMP baseia-se na avaliação dos propágulos infectivos em diluições seriadas até sua extinção e fornece um método rápido para acessar o potencial de inóculo micorrízico com fins comparativos. No entanto, esse acessa apenas o número de células viáveis em um inoculante, mas não provê informações do fitness dessas células e nem reflete sua habilidade para sobreviver no campo, após a aplicação do inoculante (Herrmann \& Lesueur, 2013). Variação no número de propágulos infectivos acessados pelo NMP também foi verificada em outros estudos de produção de inoculante micorrízico on farm, e o NMP encontrado neste estudo apresentou valores maiores do que aqueles encontrado por Gaur et al. (2000) e menores do que os registrados por Douds Jr.et al. (2006; 2008). Entretanto, o NMP do inoculante produzido tendeu a ser maior do que os registrados para solos de floresta (Guadarrama et al., 2008), áreas agrícolas (Wang et al., 2008) e áreas degradadas
(Carneiro et al., 2012). Do ponto de vista prático, embora o inoculante produzido neste estudo não tenha alcançado o nível de propágulos infectivos esperados para um sistema de produção massal de FMAs, o número de propágulos fúngicos dele pode propiciar o estabelecimento da colonização micorrízica quando aplicado em determinadas condições do campo (áreas degradadas pela mineração) ou em viveiro (em substratos inertes), cujo potencial de inóculo é baixo.

No sistema de produção de inoculante micorrízico on farm há vários fatores que influenciam a qualidade do inoculante produzido, o que exige abordagem multidisciplinar para otimizar o processo. Os resultados deste estudo demonstraram potencial da utilização do lodo de celulose em substratos para a produção de inoculante micorrízico pelo sistema on farm. A presença de substâncias alelopáticas na CP pode ter sido uma das razões de esse resíduo ter tido eficiência menor do que a LC. No entanto, novos ensaios são necessários para testar algumas alterações no processo da produção, visando maximizar a produção de esporos e de propágulos infectivos, entre elas, o uso de diferentes plantas hospedeiras, o teste de novas combinações de substrato, a variação no tempo de desenvolvimento das plantas e o regime de fertilização das plantas. Os sistemas de produção agrícola e de produção de mudas podem se beneficiar da associação simbiótica estabelecida entre as plantas e os FMA, principalmente na diminuição do uso de fertilizantes fosfatados. O desenvolvimento de um inoculante micorrízico pelo método on farm com o uso de resíduos do setor florestal como apresentado neste estudo representa um primeiro passo para que essa tecnologia seja incorporada nos sistemas produtivos.

\section{CONCLUSÕES}

1. O resíduo de lodo de celulose teve potencial para ser incorporado no substrato para a produção de inoculante micorrízico no sistema on farm.

2. O número de esporos dos FMAs inoculados não foi produzido homogeneamente em todas as partes do sistema on farm apresentado, demonstrando tendência de diminuir a densidade de esporos com a profundidade nas unidades experimentais.

3. A esporulação e a produção de propágulos viáveis de D. heterogama PNB102A em substrato contendo lodo de celulose demonstraram o potencial de membros da família Gigasporaceae serem componentes de um inoculante micorrízico.

\section{AGRADECIMENTOS}

Este estudo foi financiado pela Fundação de Amparo à Pesquisa e Inovação do Estado de Santa Catarina 
(FAPESC) e Conselho Nacional de Desenvolvimento Científico e Tecnológico (CNPq) (Edital REPENSA 22/ 2010). O primeiro autor agradece à CAPES, pelo financiamento da bolsa de mestrado; e o segundo autor, ao CNPq, pela bolsa de produtividade (Processo 302343/2012-1). Ao Diego Pasqualini e Thiago Roberto Schlemper, pelo auxílio na montagem e colheita do experimento; e à Andreza Pozzan, pelas fotos.

\section{LITERATURA CITADA}

ALEXANDER, M. Most-probable-number method for microbial populations. In: BLACK, C.A. ed. Methods in soil analysis. Madison, American Society of Agronomy, 1965. p.1467-1472.

ASSOCIAÇÃO BRASILEIRA DE PRODUTORES DE FLORESTAS PLANTADAS - ABRAF. Anuário estatístico da ABRAF - ano base 2011. Brasília, 2012. 150p.

BAGYARAJ, J.D. \& STÜRMER, S.L. Fungos micorrízicos arbusculares (FMAs). In: MOREIRA, F.M.S.; HUISING, E.J. \& BIGNELL, D.E., eds. Manual de biologia dos solos tropicais. Lavras, Universidade Federal de Lavras, 2010. p.205-225.

BARRETTO, V.C.M. Resíduos de indústria de celulose e papel na fertilidade do solo e no desenvolvimento de eucalipto. Jaboticabal, Universidade do Estado de São Paulo, 2008. 78p. (Tese de Doutorado)

BLUM, L.E.B. Benzaldehyde, kudzu (Pueraria lobata), velvetbean (Mucuna deeringiana), and pine bark for the management of Rhizoctonia solani and Sclerotium rolfsii. Auburn, Auburn University, 1998. 230p. (Doctoral Thesis)

BRASIL. Lei 12.305 de 02 de agosto de 2010. Institui a Política Nacional dos Resíduos Sólidos - PNRS e dá outras providências. Disponível em: <http://www.planalto.gov.br/ ccivil_03/_ato2007-2010/2010/lei/l12305.htm>. Acesso em 23 Jun. 2012.

BELlote, A.F.J.; SILVA, H.D.; FERREIRA, C.A. \& ANDRADE, G.C. Resíduos da indústria de celulose em plantios florestais. Bol. Pesq. Flor., 37:99-106, 1998.

CARNEIRO, R.F.V.; CARDOZO-JÚNIOR, F.M.; PEREIRA, L.F.; ARAÚJO, A.S.F. \& SILVA, G.A. Fungos micorrízicos arbusculares como indicadores da recuperação de áreas degradadas no Nordeste do Brasil. R. Ci. Agron., 43:648$657,2012$.

DALPÉ, Y. \& MONREAL, M. Arbuscular mycorrhiza inoculum to support sustainable cropping systems. Crop Manage. Doi:10.1094/CM-2004-0301-09-RV.

DOUDS Jr., D.D., NAGAHASHI, G. \& HEPPERLY, P.R. Onfarm production of inoculum of indigenous arbuscular mycorrhizal fungi and assessment of diluents of compost for inoculum production. Bioresour. Technol. 101:23262330, 2010.

DOUDS Jr., D.D.; NAGAHASHI, G.; PFEFFER, P.E.; KAYSER, W.M. \& REIDER, C. On farm production and utilization of arbuscular mycorrhizal fungus inoculum. Can. J. Plant Sci., 85:15-21, 2005.
DOUDS Jr., D.D.; NAGAHASHI, G.; PFEFFER, P.E.; KAYSER, W.M. \& REIDER, C. On-farm production of AM fungus inoculum in mixtures of compost and vermiculite. Biores. Technol., 97:809-818, 2006.

DOUDS Jr., D.D.; NAGAHASHI, G.; REIDER, C. \& HEPPERLY, P.R. Choosing a mixture ratio for the on-farm production of AM fungus inoculum in mixtures of compost and vermiculite. Compost Sci. Utiliz., 16:52-60, 2008.

FABRES, A.S.; COUTO, C. \& CONCEIÇÃO, D.A. Uso de resíduo industrial de celulose em florestas. In: GUERRINI, I.A.; BELLOTE, A.F.J. \& BÜLL, L.T., eds. SEMINÁRIO SOBRE USO DE RESÍDUOS INDUSTRIAIS E URBANOS EM FLORESTAS. Botucatu, FEPAF/UNESP, 1994. p.121-140.

FERREIRA, C.E.M.; CARRASCO, E.V.M. \& HELMEISTER, J.C. Tecnologia de adesivos poliuretanos: Propriedades e aplicações em madeiras. In: ENCONTRO BRASILEIRO EM MADEIRAS E ESTRUTURAS DE MADEIRAS, São Carlos, 1989. Anais... São Carlos, LaMEM/EESC-USP, 1989. p.39-74.

FELDMANN, F. \& GROTKASS, C. Directed inoculum production - shall we be able to design populations of arbuscular mycorrhizal fungi: to achieve predictable symbiotic effectiveness? In: GIANINAZZI, S.; SCHUEPP, H.; BAREA, J.M. \& HASELWANDTER, K., eds. Mycorrhizal technology in agriculture. Basel, Birkhäuser, 2002. p.261-279.

FINLAY, R.D. Ecological aspects of mycorrhizal symbiosis: With special emphasis on the functional diversity of interactions involving the extraradical mycelium. J. Exp. Bot., 59:1115-1126, 2008.

GAUR, A.; ADHOLEYA, A. \& MUKERJI, K.G. On-farm production of VAM inoculum and vegetable crops in marginal soil amended with organic matter. Trop. Agric., 77:21-26, 2000.

GAZEY, C.; ABBOTT, L.K. \& ROBSON, A.D. The rate of development of mycorrhizas affects the onset of sporulation and production of external hyphae by 2 species of Acaulospora. Mycol. Res., 96:643-650, 1992.

GERDEMANN, J.W. \& NICOLSON, T.H. Spores of mycorrhizal endogene species extrated from soil by wet sieving and decanting. Trans. British Mycol. Soc., 46:235244, 1963.

GIOVANNETTI, M. \& MOSSE, B. An evaluation of techniques for measuring vesicular arbuscular mycorrizal infection in roots. New Phytol., 84:489-500, 1980.

GUADARRAMA, P.; ARGÜERO, S.C.; ZAPATA, J.A.R.; RICALDE, S.L.C. \& SÁNCHEZ, J.A. Propagules of arbuscular mycorrhizal fungi in a secondary dry forest of Oaxaca, Mexico. R. Biol. Trop., 56:269-277, 2008.

HERRMANN, L. \& LESUEUR, D. Challenges of formulation and quality of biofertilizers for successful inoculation. Appl. Microbiol. Biotechnol., 97:8859-8873, 2013.

IJDO, M.; CRANENBROUCH, S. \& DECLERCK, S. Methods for large-scale production of AM fungi: Past, present, and future. Mycorrhiza, 21:1-16, 2011. 
KOSKE, R.E. \& GEMMA, J.N. A modified procedure for staining roots to detect VA mycorrhizas. Mycol. Res., 92:488-505, 1989 .

MILLER, R.M.; REINHARDT, D.R. \& JASTROW, J.D. External hyphal production of vesicular-arbuscular mycorrhizal fungi in pasture and tallgrass prairie communities. Oecologia, 103:17-23, 1995.

MORTON, J.B. Properties of infective propagules at the suborder level (Glominae versus Gigasporineae). INVAM Newsletter 3, September 1993.

NOVAIS, C.B. \& SIQUEIRA, J.O. Aplicação de formononetina na colonização e esporulação de fungos micorrízicos em braquiária. Pesq. Agropec. Bras., 44:496-502, 2009.

ODNEAL, M.B. \& KAPS, M.L. Fresh and aged pine bark as soil amendments for establishment of highbush blueberry. HortScience, 25:1228-1229, 1990.

PASQUALINI, D.; UHLMANN, A. \& STÜRMER, S.L. Arbuscular mycorrhizal fungal communities influence growth and phosphorus concentration of woody plants species from the Atlantic rain forest in South Brazil. For. Ecol. Manage., 245:148-155, 2007.

PATREZE, C.M. \& CORDEIRO, L. Nodulation, arbuscular mycorrhizal colonization and growth of some legumes native from Brazil. Acta Bot. Bras., 19:527-537, 2005.

SCHLEMPER, T.R. \& STÜRMER, S.L. On farm production of arbuscular mycorrhizal fungi inoculum using lignocellulosic agrowastes. Mycorrhiza, 24:571-580, 2014.

SHARMA, M.P. \& ADHOLEYA, A. Developing prediction equations and optimizing production of three AM fungal inocula under on farm conditions. Exp. Agric., 47:529-537, 2011.

SIEVERDING, E. Vesicular-arbuscular mycorrhiza management in tropical agrosystems. Eschborn, Deutsche Gesellschaft für Technische Zusammenarbeit (GTZ), 1991. 371p.
SIQUEIRA, J.O.; SAFIR, G.R. \& NAIR, M.G. Stimulation of vesicular-arbuscular mycorrhiza formation and growth of white clover by flavonoid compounds. New Phytol., 118:87-93, 1991.

SIQUEIRA, J.O.; CARNEIRO, M.A.C.; CURI, N.; ROSADO, S.C.S. \& DAVIDE, A.C. Mycorrhizal colonization and mycotrophic growth of native woody species as related to successional groups in southeastern Brazil. For. Ecol. Manage., 107:241-252, 1998.

SIQUEIRA, J.O.; LAMBAIS, M.R. \& STÜRMER, S.L. Fungos micorrízicos arbusculares - características, associação simbiótica e aplicação na agricultura. Biotecnol. Ci. Desenv., 25:12-21, 2002.

SIQUEIRA, J.O. \& SAGGIN-JÚNIOR, O.J. Dependency on arbuscular mycorrhizal fungi and responsiveness of some Brazilian native woody species. Mycorrhiza, 11:245-255, 2001.

SMITH, S.E. \& READ, D.J. Mycorrhizal symbiosis. 3.ed. San Diego, Academic Press, 2008. 787p.

SREENIVASA, M.N. Selection of an efficient vesiculararbuscular mycorrhizal fungus for chili (Capsicum annuum L.). Sci. Hortic., 50:53-58, 1992.

STEPHENS, J.H.G. \& RASK, H.M. Inoculant production and formulation. Field Crops, 65:249-258, 2000.

ZANGARO, W.; BONONI, V.L.R. \& TRUFEN, S.F.B. Mycorrhizal dependency, inoculum potential and habitat preference of native woody species in South Brazil. J. Trop. Ecol., 16:603-622, 2000.

WANG, Y.Y.; VESTBERG, M.; WALKER, C.; HURME, T.; ZHANG, X. \& LINDSTRÖM, K. Diversity and infectivity of arbuscular mycorrhizal fungi in agricultural soils of the Sichuan Province of mainland China. Mycorrhiza, 18:59-68, 2008. 